\title{
Exploring Meaning: Verb Semantics and Quality
}

\author{
Natalie Gridina \\ National Research University Higher School of Economics \\ Correspondence concerning this article should be addressed to Natalie Gridina, 26/1 Ak. Skryabina Str., \\ 143, Moscow, Russin Federation. E-mail: gnv1401@gmail.com
}

\begin{abstract}
This paper examines the syntagmemic structure of verbs and their correlations with their logicalsemantic quality drawing on the methods of componential analysis and morphothemic analysis proposed by A.I. Fefilov. The former approach helps us to single out the word standard semes, which are fixed in a language, whereas the latter is particularly useful in studying the nature of word semantics, its structure, and correlation with the concept and category of thought. Our research suggests that the method of morphothemic analysis provides a complex, multifaceted, in-depth analysis of the semantic structure of the verb. One hypothesis raised by the study is that the verb reveals the processual peculiarities of the quality. The logical-semantic quality is fixed in verb semantics in terms of its propositional relations, which are implicit in a verb. The results show that the quality represented by a verb is concomitant as it goes together with relationality, the main component of a verb syntagmeme. Our research studied the effect of the verbal part of speech categorization on the manifestation of quality in a language. The work provides new insights into the semantic structure of language units, exploring for the first time the logical and semantic qualities of verbs, which were subjected to a systematic morphothematic analysis. A further study could address the comparative investigation of the category of quality in different languages in terms of its translation. Additionally, this would enable an identification of the main trends of representing quality with the help of a verb in different languages and would distinguish a new unconventional syntagmeme that changes and modifies the category of quality in speech and consequently find out the ways in which a language determines categories of thought.
\end{abstract}

Keywords: semantics, verb, syntagmeme, morphothematic, thinking, concept, and implicit semantic component

Quality is a logical category that pervades all spheres of our life. Life would be grey and boring if there were not quality in it. We suggest that quality is expressed, fixed, manifested, represented on a lot of language levels and inter-levels as well. We attempt to show that even a verb whose nature is not to represent the logical-semantic quality in its pure form includes a qualitative component in its syntagmemic structure.

We distinguish two basic approaches within structural semantics currently adopts in research into verbal semantics in different languages. ${ }^{1}$ One is the approach of linguistic fields and the other is the componential analysis of word semantics. Each approach makes an important contribution to the study of quality in language and the identification of its place in the semantic system. First, the componential approach aims at exploring each seme in the semantic structure (Spiewok, 1980; Schippan, 1980; Givon,

\footnotetext{
${ }^{1}$ This paper uses the term "verbal”, denoting “verbs and verb-like expressions" suggested by Verschueren (1981).
}

1970; Schippitsina, 1972). Second, the theory of semantic fields focuses on the correlation of one semantic category with different means of its formal manifestation on various language levels (Geeraerts, 2013; Trier, 1931; Weinreich, 1966; Porzig, 1967; Bondarko, 1991), which allows us to turn to intercategoric relationships in language and thinking.

However, the theory of semantic fields and componential analysis encounter various problems. We agree with Verschueren (1981), who points out the difficulties faced by componential analysis. Firstly, it is unclear which pole of the binary contrast should be taken as the descriptive point. Secondly, "the alleged atomicity" of certain semantic features is itself a point of dispute. Thirdly, Verschueren raises the question of how detailed the analysis should be in terms of semantic features. Fourthly, he points out "the dubitable existence of a universal set of semantic features belonging to some universal mental language" Verschueren, Jef, (1981, p. 150). This set of semantic 
features could be random, as many scholars have suggested. Moreover, the structural theory of lexical fields attempted to solve the problem of the semantic relationship between lexical items (Vassilyev, 1974; Coseriu \& Geckeler, 1974; Lehrer, 1974; Lounsbury, 1964; Goodenough, 1965), but there is still some uncertainty about the way in which conceptual fields can be lexicalised. It is still unclear how to define the boundaries of word meaning (Verschueren, 1981).

The logical and semantic qualities do not always match with the lexical and syntactic qualities, which disagree with both componential and semantic field approaches. Although the theory of semantic fields reveals the possibility of expressing quality by linguistic means, it does not fix the ways quality is manifested through different language forms and their usage in various speech acts. The field and componential approaches could thus be considered one-sided, as they do not examine the interdependence of logical and semantic categories. We suggest, instead, using a method that will let us explore word semantics in terms of the correlation between language units and their conceptual representations. We address this issue through the analysis, which gives us a formalsemantic unity similar to its semiotic character. This unity could be taken as an ideal instrument for a complex, multi-faceted, synthetical, and multi-level analysis. Our findings lead us to conclude that the morphothematic analysis advanced by Fefilov (1997) meets these requirements.

\section{Materials and Methods}

\section{Literature Review}

In the present study we investigate the correlation of quality with other logical and semantic categories on a language and speech level, and then define the place of a complementary quality of a verb. The present work also describes the syntagmemic verb structure, which includes complementary quality. We explore the ways verb quality is manifested in language, by establishing morphothemantic classes, where quality is expressed with varying intensity and on different language levels. This study provides new insights into the semantic structure of verbs by analysing, for the first time, verbs with logical and semantic qualities.

A substantial body of literature was reviewed in order to understand how the semantic structure of a verb has been explored with regard to the logicallinguistic category of quality in the English languages. A popular method to study verb semantics is the functional-semantic field approach. Bondarko (1991) emphasises the diversity of the verb's structural types. "The system of language means is seen through the semantic principle of their grouping. It is the objective foundation of the grouping of language means employed in speech. The description goes not only from form to meaning (from means to function), but also from meaning to form (from functions to means)" (Bondarko, 1991, p. 2). Functional grammar integrates language means of different levels within functional units. Various language units (morphological, syntactical, word-formation, lexical, etc.) expressing one function are considered in this approach (see more Zvegincev, 1977). Collectively, these studies outline a critical role for exploring language units on various levels, referring to their similar function and interconnection with other units from different lexical-semantic fields. For the purpose of our comparative investigation, we suggest that units should be considered not only from various levels but also in-between these levels since different languages have different grammaticality and lexicalisation of concepts. We assume that the concept is affected not only by extra-linguistic factors but also by the semantics of the form, which influence the logicalsemantic concept.

A large and growing body of literature has investigated the semantic structure of a verb in terms of its syntactic function/behaviour and the number of arguments it can represent. For example, Levin (1993) classifies over 3,000 English verbs with respect to a wide range of syntactic alternations that reflect verb meaning: first, the alternate ways in which verbs can express their arguments are shown; second, the verbs which share a kernel meaning and syntactic behaviour are classified. Furthermore, Levin and Hovav (2010) divide verbs into action verbs and state verbs, with the latter split into manner verbs and result verbs. In Doering and Malcolm (2015), the authors rely on Levin's verb classifications and. for each verb, provide the possible argument structure and a logical representation of their semantics. This work also presents the ontology of different types of verbs denoting changes of state. The authors use both linguistic and visual features to predict the changes of state by denoting a verb to help a computer to understand a human's instruction in the kitchen domain. Overall, there seems to be some evidence to indicate that syntax (argument structure) helps to categorise verbs into classes of verbs with semantic similarities. The above-mentioned works aimed at discovering how verbal meanings could be presented through the system of grammatical categories (see more Mustafina et al., 2015; Holmes, 1990, 1999; Kratzer, 2002). Taken together, these studies provide important insights into the correlation of grammar and lexical semantics.

Apart from these studies, no works have been found that explore quality in a verb's semantic structure; moreover, none has studied the quality that a verb expresses implicitly, which is intertwined with other 
semantic components in the semantic structure of a verb as an implicit semantic component. Since the verb is thought to have a very complex, dynamic structure (Kratzer, 2002; Levin, 1993), it is important to single out all the elements that the verb can manifest, represent, and express. It is interesting to uncover the nature of a qualitative component in the semantic structure of a verb, its representative capacity, connection with other logical-semantic categories within a verb structure, and how is might change while referring to the logical quality (concept of quality).

\section{Methodology \\ 1. Basic Terms of the Morphothematic Analysis}

In this section we will outline some basic terms, principles of the methodology, and present some analysis of the semantic structure of a word. This research employs the method of componential analysis and morphothemic analysis, suggested by A. I. Fefilov (1997). The former approach helps us to single out the word standard semes, which are fixed in a language, whereas the latter is particularly useful in studying the nature of word semantics, its structure, and correlation with the concept, category of thought. This mixed approach provides insight into the correlation of quality with other logical semantic categories on different levels, enabling us to define the status of quality and describe its position in the syntagmemic structure of a verb. We suggest that the method of morphothemic analysis is well-suited as it gives a complex, multifaceted, in-depth analysis of the semantic structure of the verb.

According to this approach, the concept receives a language status on different levels of language representation (Fefilov, 2002, p. 13). On the semantic level, the concept acquires semantic properties (components) in a language, thus syntagmeme is formed. The thought/idea is fixed in a semantic structure of a word. On a formatting level, the level of exteriorization, the semantic components are fixed on different levels of language forms. The exteriorization process is "the movement of a thought along the formal language surface and at the same time it gets a semantic brightening" (translated from A. I. Fefilov, 2002, p. 12). This methodology introduces an operational unit or the ideal model for linguistic analysis. It is a morphotheme, an acoustic syntagmemic unity (morph is a form, theme is the semantic base) (Fefilov, 1997, p. 4). The morphothematic analysis is the description of the result of the implementation of the conceptually conscious structure and content in a language, namely: (1) manifestation of the structuralised semantic processes of the concept in a language in a form of asyntagmeme; (2) systematization of the ways of formatting the syntagmemic properties and their types of correlation.
While a variety of definitions of the key terms, such as the units of the lexical semantics and concepts, have been suggested (Geeraerts, 2013; Closs Traugot \& Dasher, 2004), this paper follows the suggestions of Fefilov (1997) who identified them as the following. The units of lexical semantics are logical-semantic categories (similar to logical categories which are fixed in a language); structural properties that fix the place of concepts or conceptual elements in the structure; modified functional properties that reflect the types of logical and thinking categories and their correlation; content properties that present the informative volume of implemented- in-language concepts. The above-mentioned properties are united on different semantic levels, which are organized in a linear syntagmeme. Prior to Fefilov, the term 'syntagmeme' had been used by Longacre $(1960,1964,1965 a)$ to refer to a grammatical unit of tagmemic theory. However, Professor Fefilov attaches a different meaning to this notion, making it is necessary to clarify here exactly what we intend by this term. According to Fefilov, a symtagmeme is a set of conceptual elements fixed in a language. The concept acquires the status of semantic properties on the firstlevel of language implementation. It results in the formation of a syntagmeme, which is a set of semantic characteristics of a word organized linearly. Thus, thought is fixed in language in a static semantic structure, or "folded, contracted proposition chain" (Fefilov, 1997). It is further necessary to clarify that we understand 'concept' as the information about possible denotations, their place in the system of realias, their value in the universe which the sign renders (Schreider, 1974, p.10).

\section{Semantization as the First Step of Morphothe- matic Analysis}

According to morphothematic analysis, we distinguish two levels: in-language-implementation and in-speech representation. This paper deals with the former level where we single out two stages: semantization and formatting. On the semantic level, the concept acquires semantic properties (components) in a language, thus syntagmeme is formed. The thought/idea is fixed in a semantic structure of a word.

To illustrate this first step of the morphothematic analysis, semantizisation, which is the focus of the present paper, we are going to study the syntagmemic structure of some units which contain a qualitative component in its structure. As we have mentioned above, every syntagmemic component goes through four stages of semantizisation of the concepts. They are as follows:

1. Structural, or positional;

2. Logical categorical;

3. Modifying or/and functional 
4. Informative.

For example, the syntagmeme of the word "illness" is

I. A state, which

II. Characterizes

III. Somebody

IV. Having certain properties.

The syntagmeme includes such components as Quality 1 + Possessivity + Substantiality + Quality 2. Here Quality 1 is the nuclear component that has the highest prominence and the initial position, then Possessivity takes an intermediate position, Substantiality has an adjacent one and Quality 1 occupies an arresting position. Also each component is modified. Quality 1, 2 is an absolute quality, physical state. Substantiality is an animated subject. Possessivity is a modified property of the relationality. Each syntagmemic component has its own informative volume (content).

I. Physical state, mood,

II. Having certain characteristic features, peculiarities;

III. Some person, creature;

IV. Unhealthy, susceptible to disease. table.

We can present the syntagmeme in the following

The morphothematic analysis shows us that there is no "pure' qualitative syntagmeme. Quality is actively involved in other syntagmemes. It is mainly concomitant.

Compare these units:

1. illness of a man;

2. ill person;

3. the person has a disease;

4. the person is ill.

The logic-semantic quality is presented here in different ways.

In (2) the syntagmeme includes the following categories Sub ("Somebody") + Rel_Exist. In (1) the syntagmeme is fixed with such categories Quality 1 + Quality 2 + Rel._Poss + Sub I. "some II state" III

Table 1

The syntagmeme of the word "illness"

\begin{tabular}{|c|c|c|c|c|c|c|c|}
\hline & I & & I & & III & & IV \\
\hline & State that & & characterizes & & somebody & & s having certain properties \\
\hline \multirow[t]{2}{*}{1} & $\begin{array}{l}\text { Structural, or } \\
\text { positional }\end{array}$ & 1 & Structural, or positional & 1 & Structural, or positional & 1 & Structural, or positional \\
\hline & initial & + & Intermediate & + & adjacent & + & arresting. \\
\hline \multirow[t]{2}{*}{2} & $\begin{array}{l}\text { Logical semantic } \\
\text { category }\end{array}$ & 2 & Logical semantic category & 2 & Logical semantic category & 2 & Logical semantic category \\
\hline & Quality 1 & + & Relationality & + & Substantiality & + & Quality 1 \\
\hline \multirow[t]{2}{*}{3} & modifying/functional & 3 & modifying/functional & 3 & modifying/functional & 3 & modifying/functional. \\
\hline & Absolute quality & + & characteristic. & + & animated & + & Physical state. \\
\hline 4 & Physical state, mood, & 4 & $\begin{array}{l}\text { Having certain } \\
\text { characteristic features, } \\
\text { peculiarities; }\end{array}$ & 4 & Some person, creature & 4 & $\begin{array}{l}\text { Unhealthy, susceptible to } \\
\text { disease }\end{array}$ \\
\hline
\end{tabular}

"is characteristic of" IV "somebody". The qualitative property is the most prominent. The (1) unit manifests the quality of substantiality. Sub_Sub ("someone") + Exist. ("is") + Qual.1 ("in some") + Qual.2 ("state"), where Quality 1 is constant, whereas Quality 2 is temporary, cf. a healthy person. This unit manifests substantiality with a qualitative component.

In (3) the syntagmeme manifests Sub.("somebody") + Exist. ("is") + Qual.1 ("in some") + Qual.2 ("state") + Temp. ("for some period", "sometimes", does not primarily correlate with actionality but with temporality. The syntagmeme is qualitative-temporal.

In (4) the syntagmemepresents Sub. ("somebody") + Exist. ("is") + Qual.1 ("in some") + Qual.2 ("state") + Temp. ("at this moment"). The difference between (3) categorization) makes the qualitative component more dynamic.

\section{Formatting as the Second Stage of Morphothematic Analysis.}

In terms of the morphothematic methodology, the syntagmeme is fixed in a sound image, which consists of different formats, or forms on the formatting level of the manifestation of a concept into a language. As the result, a two-facet unit is formed. Formatting goes in two ways: lexicalization (nominalization and wordformation) and grammaticalization (morphological and syntactic processes) (Fefilov, 1997, p. 57). The following levels are singled out on the formatting stage.

1. Categorical-semantic level (CSP), the basic one. The syntagmeme, which acquires the main "thematic" position and semantic priority, acquires a certain form.

2. Nomination-semantic property, secondary or background level of the formatting process. "occasionally"). Here part of speech categorization and (4) is that part of the speech categorization (verb 
One of the adjacent, arresting and intermediate properties becomes prominent on this level, which acquires a name form, as a rule, root format. And the formatted syntagmeme motivating the word, becomes its "inner form" (Humboldt, 1984, p. 100)

3. Determinative-semantic property, level of a secondary or adjacent nomination. The syntagmeme is fixed in a separate word-format, which is used with the main basic nominative unit distantly as its attribute, adverbial modifier or object.

4. Associative-semantic property, the syntagmeme is not fixed in a special format, but is associated with the name itself. The syntagmeme is implied. In this paper 'implicitness' refers to all cases when meaning is not revealed through the language forms.

To illustrate the above mentioned formatting levels we suggest continuing the morphothematic analysis of the word "illness". The initial qualitative property is the most semantically prominent and gets the status of a categorical-semantic property (CSP), and the arresting component Quality 2 (certain quality, the informative content), coinciding with the format of the word -ill- and becoming its motivation, gets the status of a nomination-semantic property (NSP). So its morphotheme is CSP_Quality + NSP Quality. In contrast the morphotyeme of the word "decorate" is CSP_Actioning + NSP_Quality_Object + ASP_Sub Obj and the morphotheme of "put Christmas tree decoration on a Christmas tree" is CSP_Actioning + ASP_Sub_OBj + ASP_Location.

We have analyzed 1500 Russian verbs and 1300 Russian verbs selected from dictionaries. Besides that we examined 1600 Russian pieces of literary texts and their translations into English by native speakers, as well as 1200 pieces of literary texts in English and their translations into Russian by Russian speakers. All the material was selected through a continuous sampling method.

\section{Results and Discussion}

This section is divided into subsections where we will attempt to answer the research questions stated in the Introduction. First we will deal with the semantic structure of a verb with a qualitative component in terms of the morphothematic analysis and classify verb syntagmemes. Then we will explore the formatting level of semantisation of quality in a language and will look into the verbal part of speech categorization and its impact on quality in a language. And finally, we will examine the influence of language peculiarities on quality in English.

\section{Syntagmemic Structure of a Verb}

The first set of questions is aimed at studying the syntagmemic structure of a verb with a qualitative component. In terms of morphothematic analysis the semantic structure of a verb is the following:

Semantics of the form

The syntagmeme

The informative content

Semantics of the form includes morphological, grammatical, word-formation intra-linguistic properties (meaning of affixes) which determine the word semantics; the syntagmeme is a sum of indepth logical-semantic categories, which have a linear presentation and are organized paradigmatically; informative content is a sum of properties which fix the content of the implemented-in-a-language categories. We will illustrate the semantic structure of a verb by analysing the English word "aging". One of the components of the syntagmeme "become old" (Rel Becomming + Quality (Sub Sub) becomes explicit as a nominative-motivating-semantic property (NSP) through the root "age"; the syntageme gets a verbal part-of-speech categorization, implementing a dynamic property in the language. Syntagmemes are fixed paradigmatically, getting four-dimensional interdependence, namely, in terms of their (1) position (prominence), (2) logical category, (3) modification (function) and (4) content. We illustrate this schematically in Table 2.

Table 2

The syntagmemic structure of the verb "to age" in terms of morphothematic analysis

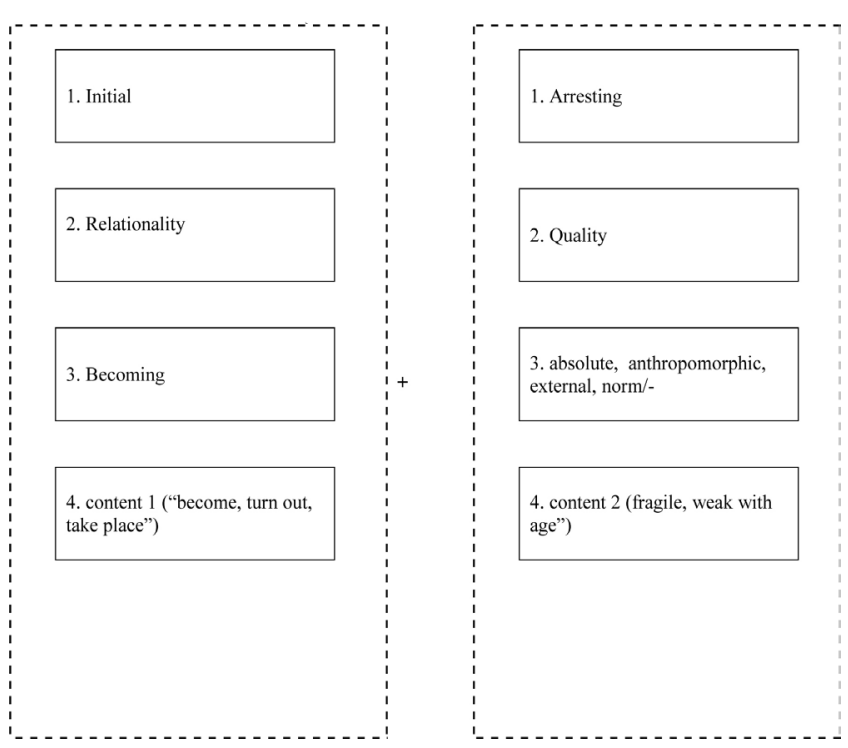

Numerous examples illustrate that the verb implements the logical-semantic category of relationality, whose types are the following: 
1. actioning (process, action, influence);

2. transportation (movement, shifting, transformation);

3. location (relation to a place, location);

4. possessing (relation to possession, owning);

5. locution (speaking);

6. becoming;

7. existentiality (existence);

8. exhibitionality (manifestation, exhibition, exercise, this term was introduced by us from the English word "exhibit" - show a particular feeling, quality).

The research distinguishes the following classes of verb syntagmemes with a qualitative component due to the type of the relator, which is manifested in English by means of the syntagmeme:

(1) qualitative-actioning class that characterises the action, for example, (a) roar, burst into laughter and others (b) sing loudly, drink hurriedly, answer slowly etc. (c) clatter, brawl, riot, etc.

(2) actioning-factual-qualitative class, whose syntagmeme is "to add an object some quality", for example, to clean, paint), paint white, boil, make warm etc.

(3) existential-qualitative class, whose syntagmeme is "to be in some state", for example, be horrified, be afraid, be worried, etc.

(4) transportation-qualitative class, whose syntagmeme is "to make movement in a certain way", for example, to limp, spread, toddle.

(5) transportation - location - qualitative class, for example, lash - "move around a place being worried", trudge, fuss, etc.

(6) existential-qualitative class "be in some state", for example, be patient, be tolerant, be stubborn etc.

(7) location-qualitative class "be located/situated in a certain way", where location is a relationality, relation of concepts in space, for example, hang around, lie about etc.

(8) becoming-qualitative class, which presents the syntagmeme "formation of a certain quality", for example, blush, grow white, wane etc.

(9) locution-qualitative class, whose syntagmeme is "to do speaking in a certain way", for example, whisper = "speak in a whisper", grumble $=$ "speak in a querulous way", mumble = "do speaking indistinctly etc.

(10) exhibiting-qualitative class, "demonstrate/ give some quality", for example, shine - "give light", similar words are glitter, sparkle, love, respect, value, adore, etc.

It can be seen from the above verb classes that the nature of the verb does not aim at representing the logical-semantic quality in its pure form. It takes the final or adjacent position in a word syntagmeme. The verb reveals processual peculiarities of the quality.
The logical-semantic quality is fixed in verb semantics in terms of its propositional relations, which are implicit in a verb. The quality represented by a verb is concomitant as it goes together with the relationality, the main component of a verb syntagmeme.

\section{Formatting Stage of Semantization}

The second set of questions concentrates on the formatting level of semantization of quality. The part-of-speech criterion of the verb is "grammatical action". It is so-called formal meaning, which characterizes a verb as part of speech. The part-ofspeech action correlates with categorical-semantic relation of the subject to the action, directed onto the object or itself (compare "to wash oneself", "to cut something"), process (is working), quality ("to straighten") etc. The part-of-speech actioning unifies different logical-semantic properties (Fefilov, 1977, p. 77). This can be illustrated briefly by our analysis of some verbs showing how the syntagmeme of the verb is transformed into a morphotheme, which is a formal and semantic semiotic model of a language unit. We will put the metalanguage in inverted commas; the $\rightarrow$ shows the transition of the syntagmeme into the morphotheme:

- "sadden" - "to feel/have a certain state of sadness" - Rel_Exhibit. + Quality 1 + Quality 2 $\rightarrow$ CSP_Possession +NSP Quality 2;

- "sob" - "to shed tears producing much noise" Rel_Act. + Sub_Factual + Quality_Act. $\rightarrow$ CSP_Act +ASP_Quality_Actioning+ASP_Sub;

- to freeze - "become motionless" - Rel_Becoming +Quality $\rightarrow$ KSP_Becoming +NSP_Quality;

- to redden - "to become red" - Rel_Becoming + Quality $\rightarrow$ CSP Becoming+NSP Quality;

- to polish- "to make the surface smooth" - Rel. Actioning + Sub_Obj + Quality_Result $\rightarrow$ CSP Actioning +DSP_Quality (ASP_Sub + DSP_Quality;

- to cure- "to make a person healthy" - Rel Act + Sub_Obj+Quality_Result $\rightarrow$ CSP_Act + ASP $_{-}$ Sub_Obj + ASP_Quality.

As can be seen from the examples above, the verb morphotheme can be explicated in a language on the formatting level as:

1. An associative-semantic property, which does not have a definitive form on the nomination level, but is fixed in a word implicitly. Here is one more example: "whip" = to do an action with a flexible instrument; to do a destructive action that results in small parts. Moreover, a verb can include quality potentially as, for example, verbs of saying tell, speak, pronounce, utter etc. The ASP can have different degrees of certainty in a syntagmeme; for example, in the verb "mutter" the degree of expressing quality 
of speaking is higher than in "pronounce", "speak", "tell". Here the logical- semantic property of quality can be easily predicted, is more certain ("to mutter" - to speak in an unclear way).

2. A nomination-semantic property, which becomes explicit with a certain language form (roots, suffixes, prefixes, postpositives), for example, CSP Rel_Locution + NSP_ Quality (whisper, cry, scream, overwork). English verbs that represent a qualitative characteristic of a person's state are formed from qualitative nouns and adjectives by means of suffixes and conversion, for example, brighten, frighten, hearten, horrify, glorify, encourage, enjoy, idolize, overshadow, anger, chuckle, comfort, disgrace, disgust, delight, distress, fame, insult, honour, love, nerve, etc. Word-formation forms in verb-derivatives are the prefixes dis-, en-, in-, re- and the postpositives out, over, up and others. The latter, changing the verb meaning, add the seme of cause into the syntagmeme, for example, break out, cheer up, hearten up, gloat over, put out, work up, etc. Thus the wordformation analysis shows that the semantic capacity of words is determined not only by the concept, but also by the language factors as well.

3. Quality can be manifested in a separate lexeme as a determinative-semantic property (DSP), for example speak in a whisper, loudly, quietly, proudly. Here the syntagmeme is CSP Rel_Locution ++DSP_Quality. The symbol "++" shows that the syntagmeme is fixed in a separate word-format, which is used with the main basic nominative unit. Quality here is manifested in the language through an adverb part-of-speech categorization. We consider an adverb as a semantic element of a verb that acquires a formal manifestation.

The work suggests that the nature of a language, namely, the analytical one of English, determines a unique character of quality. English often represents quality discretely, by means of a nominal phrase. From our analysis of a large number of examples, we have found that discrete manifestation of quality in English renders a greater volume of the meaning in two steps by sharing the meaning between two words. Secondly, the nominal element acquires some features that contrast it with a verb in both stylistic and semantic ways. Thirdly, the analytical way of presenting quality expresses the situation in more detail:, priority is given to a qualitative component in the syntagmemic structure of a word, therefore, such logical-semantic categories as actioning, becoming, possessing, existentiality and exhibitionality are explicit and the situation is presented in a more stereotypical way. Finally, the analytical structure of English results in a wide usage of structures expressing existentiality which are presented with the verb "to be" on the formatting language level; for example, find satisfaction have admiration, grow tired, be persistent, be timid, grow old, feel warm, grow to rankness.

It should be noted that the verbal part of speech categorization might affect manifestation of quality in a language. We have found that the mood, as one of the verbal grammar categories, does not affect the language representation of the quality. As for tense forms, we have observed that the quality influences the actualization of the meanings of some tense forms. The state in its nature can be non-localized or widely localized through time. The passive voice gives great prominence to a qualitative component: the second element of the construction, Participle II, presents the quality as the state or as the result of the action. The boundedness represents a static manifestation of the quality, while atelicity represents a dynamic one. The aspect is the interdependence of the semantic components of location, time, relation, where relation refers to both location and time. Overall, the examples analysed in this work demonstrate that the sentences in which time and location are most important represent the quality, but this remains in the background of the above-mentioned linguistic components and, therefore, is not vividly manifested.

\section{Conclusion}

This investigation is aimed at studying the correlation between linguistic units and categories of thought while implementing the logical-semantic category of quality, which is explicated on the level of part of speech categorisation as a verb. We focus primarily on in-language-implementation of logical categories. We single out two stages: semantization and formatting. On the semantic level, the concept gets semantic properties (components) in a language, thus syntagmeme is formed. The thought/idea is fixed in a semantic structure of a word. On a formatting level, the level of exteriorization, the semantic components are implemented on different levels of language forms. Considering these levels, we have first described the syntagmemic structure of language units that included complementary quality, and then explored the modes of its language manifestation by establishing morphothemantic classes where it was expressed with different intensity and on different language levels.

The research has further shown that the discrete (analytical) way of presenting quality renders a greater 
volume of the meaning, in two steps, with the meaning shared between two words. The nominal element acquires some features that contrast it with a verb in both stylistic and semantic ways. Sepecifically, a priority is given to a qualitative component in the syntagmemic structure of a word: such logical-semantic categories as actioning, becoming, possessing, existentiality and exhibitionality are explicit and the situation is presented in a more stereotypical way. Finally, the analytical structure of English results in a wide usage of structures expressing existentiality which are presented with the verb "to be" on the formatting language level.

Returning to the issues posed at the beginning of this study, it is now possible to state that the morpothematic analysis examines linguistic phenomena as complex, many-sided, synthetical, and different-level units. The semantic structure of a verb is the integration of the semantics of the form, which includes morphological, grammatical, word-formation intra-linguistic properties, and the syntagmeme, which is a sum of in-depth logical-semantic categories and informative content. We propose that by considering all these levels, we can study logical and semantic categories (not only quality, but also categories of location, auctioning, quantity, substantiality, and others) that do not always match with the lexical and syntactic ones, and find ways of manifesting these categories by means of different language forms and their usages in various speech implementations.

The findings of this study have a number of important implications for future practice and theory. The work provides new insights into the semantic structure of a language unit and explores, for the first time, the verbs with logical and semantic qualities, which are subjected to a systematic morphothematic analysis. A further study could address the comparative investigation of the category of quality in different languages in terms of its translation and suggest ways or make recommendations for translators to provide a translation or interpretation that is more or less close to the original meaning. Additionally, on the level of speech representation, we can identify the main trends of representing quality with the help of a verb in different languages and distinguish a new unconventional syntagmeme, which changes and modifies the category of quality in speech; consequently, the way that a language determines categories of thought could be better understood.

\section{References}

Bondarko, A. (1991). Functional grammar: A field approach. Amsterdam, Netherlands: John Benjamin
Publishing Company.

Borisova, L. I. (1991). Problemi equivalentnosti $v$ nauchno-technicheskom perevode [The problems of equivalence in scientific and technical translation]. Moscow, USSR: Nauka.

Closs Traugot, E., \& Dasher, R. B. (2002). Regulating in semantic change. Cambridge, UK: Cambridge University Press.

Coseriu, E., \& Horst, G. (1974). Linguistics and semantics. Current trends in linguistics, 12, 103-171.

Fefilov, A. I. (1997). Morphotemny analiz yedinits yasika $i$ rechi [Morphothematic analysis of language and speech units]. Ulyanovsk, Russia: Ulyanivsk State University.

Fefilov, A. I. (2002). Metodologicheskiye osnovi morphotemnogo analisa [Methodology of the morphothematic analysis]. Ucheniye Zapiski of Ulyanovst State University, 1(7), 67-88.

Geeraerts, D. (2013). Lexical semantics from speculative etymology to structuralist semantics. Oxford Handbook Online, 560-570. doi:10.1093/ oxfordhb/9780199585847.013.0025

Givon, T. (1970). Notes on the semantic structure of English adjectives. Language, 46(4), 816-837. doi:10.2307/412258

Goodenough, W. H. (1965). Yankee kinship terminology: A problem in componential analysis. American Anthropologist, 67(5), 259-287.

Holmes, J. (1999). The syntax and semantics of causative verbs. UCL Working Papers in Linguistics, 11, 323-350. Retrieved from www.phon.ucl.ac.uk/ publications/WPL/99papers/holmes.pdf

Hovav, M. R., \& Levin, B. (2010). Reflections on manner / result complementarity. In E. Doron, M. Rappaport Hovav \& I. Sichel (Eds.), Lexical semantics, syntax, and event structure (pp. 21-38). Oxford, UK: Oxford University Press.

Humboldt, V. (1984). Isbranniye trudi po yasikisnaniyu [Selected studies on linguistics]. Moscow, USSR: Progress.

Kratzer, A. (2002). The event argument and the semantics of verbs. Amherst, MA: University of Massachusetts. Retrieved from semanticsarchive.net/.../The\%20 Event\%20Argument\%20and

Lehrer, A. (1974). Semantic field and lexical structure. Amsterdam, Netherlands: North-Holland.

Levin, B. (1993). English verb classes and alternations: A preliminary investigation. Chicago, IL: University of Chicago Press.

Lounsbury, F. (1964). The structural analysis of kinship semantics. In H. G. Lunt (Ed.), Proceedings of the North International Congress of Linguistics (pp. 7393). The Hague, Netherlands: Mouton.

Malcolm, D. (2015). Verb semantics as denoting change of state in the physical world (Unpublished dissertation). Michigan State University, East 
Lansing, MI. Retrieved from https://etd.lib.msu. edu/.../Verb_Semantics_as_Denoting_Change of State in the Physical World

Mustafina, J., Maklakova, Y., \& Magfurova, S. (2015). Lexico-grammatical principle of verbal lexemes description (on the material of the Russian language). Asian Social Science, 11(8), 52-57. doi:10.5539/ass.v11n8p52

Porzig, W. (1971). Das wunder der sprache: Probleme, methoden und ergebnisse der sprachwissenschaft [The miracle of language: Problems, methods and results of linguistics] (5th ed.). München, Germany: Francke.

Schippan, T. (1980). Arten der lexikalischen Bedeutung [The art of the lexical meaning]. Linguistische Studien, 65, 51-60.

Schippitsina, G. M. (1972). Struktura semem kachestvennih prilagatelnih I metody videleniya yeyo komponentov [The structure of qualitative adjective semes and the methods of the identification of its components] (Unpublished doctoral dissertation). Moscow State University, Moscow, Russia.
Schreider, Yu. A. (2012). Logika znakovih system: Elementi semiotiki [The logics of semiotic systems: Elements of the semiotics]. Moscow, Russia: Znaniye.

Spiewok, W. (1980). Zur typologie der seme. Fragen der semantischen Analyse. Linguistische Studien [Seme typology. Issues of the semantic analysis. Linguistic studies]. Berlin, Germany: Zentralinstitut fúr Sprachwissenschaft.

Trier, J. (1931). Der Deutsche wortschatz im sinnbezirk des verstandes [The German lexics in the concept field of the mind]. Munster, Ireland: Heidelberg.

Vasilyev, L. M. (1974). The theory of semantic fields: A survey. Linguistics, 137, 79-93.

Verschueren, J. (1981). Problems of lexical semantics. Lingua, 53, 317-351.

Weinreich, U. (1966). Explorations in semantic theory. In Th. A. Sebeok (Ed.), Current trends in linguistics (Vol. 3, pp. 395-477). The Hague, Netherlands: Mouto.

Zvegincev, V. A. (1977). Semasiologija [Semasiology]. Moscow, USSR: Moscow State University Press. 